\title{
Effect of splenic flexure mobilization performed via medial-to-lateral and superior-to-inferior approach on early clinical outcomes in elective laparoscopic resection of rectal cancer
}

\author{
Abdullah Böyük ${ }^{1}$, Ulaş Aday ${ }^{2}$, Barış Gültürk ${ }^{1}$, Ahmet Bozdağ ${ }^{1}$, Ali Aksu $^{1}$, Nizamettin Kutluer ${ }^{1}$ \\ ${ }^{1}$ Department of Surgery, University of Health Sciences, Elazıg Training and Research Hospital, Elazıg, Turkey \\ ${ }^{2}$ Department of Gastroenterological Surgery, University of Health Sciences, Elazıg Training and Research Hospital, Elazıg, Turkey
}

Videosurgery Miniinv 2019; 14 (4): 509-515

DOI: https://doi.org/10.5114/wiitm.2019.85224

\begin{abstract}
Introduction: Whether complete splenic flexure mobilization (SFM) is required remains a controversial issue and there are numerous approaches regarding the performance of this procedure.

Aim: To investigate the effect of SFM performed with a medial-to-lateral and superior-to-inferior approach on early clinical outcomes in laparoscopic resection of rectal cancer.

Material and methods: The SFM procedure was initiated by the ligation of the inferior mesenteric vein followed by dissection extending from the upper border of the pancreas to the splenic hilum through the gastrocolic space. The mesocolon was dissected in a superior-to-inferior and medial-to-lateral fashion and the presacral space was entered by dividing the inferior mesenteric artery. The procedure was completed by dividing all the splenocolic, phrenicocolic, gastrocolic, and pancreaticomesocolic ligaments.

Results: A total of 43 patients were included in the study, comprising 26 (60.5\%) men and 17 (39.5\%) women with a mean age of $58.2 \pm 13.9$ (range: 30-87) years. Of the 43 patients, 21 (48.8\%) underwent neoadjuvant chemotherapy and a diversion stoma was performed in 37 (86\%) patients. No adjacent organ injury occurred intraoperatively. Mean operative time was $271 \pm 50 \mathrm{~min}$ and mean blood loss was $144 \pm 83 \mathrm{ml}$. One (2.3\%) patient might have developed anastomotic leakage secondary to bevacizumab therapy postoperatively and developed no anastomotic stenosis in the follow-up period. Mean length of hospital stay was $9.3 \pm 4.3$ days and no mortality occurred in any patient. Conclusions: Splenic flexure mobilization performed via the superior-to-inferior and medial-to-lateral approach appears to be a safe and feasible procedure.
\end{abstract}

Key words: laparoscopy, rectal cancer, splenic flexure mobilization.

\section{Introduction}

Colorectal malignancies occur frequently and are the fourth most common cause of malignancy-related mortality in the world. It is estimated that 2.2 million new diagnoses and 1.1 million mortality cases will develop annually by 2030 [1]. Laparoscopy has recently emerged as a popular technique around the world due to its successful oncological outcomes in colorectal surgery similar to those of open surgery as well as its remarkable advantages. The description and standardization of total mesorectal excision (TME) and the use of neoadjuvant chemoradiotherapy (CRT) have led to dramatic improvement in oncological outcomes [2-4]. However, whether complete splenic flexure mobilization (SFM) is required remains a controversial issue and there are numerous

\section{Address for correspondence}

Ulaş Aday MD, Department of Gastroenterological Surgery, University of Health Sciences, Elazıg Training and Research Hospital, Elazıg,

Turkey, phone: +90 5302933895, e-mail: ulasaday@gmail.com 
approaches regarding the performance of this procedure [5-8]. The primary aim in the performance of laparoscopic complete SFM is to achieve adequate oncological resection and to ensure a tension-free anastomosis with a good blood supply. A complete SFM consists of the division of the splenocolic, phrenicocolic, gastrocolic, and pancreaticomesocolic ligaments [9-11].

Splenic flexure mobilization, whether it be open or laparoscopic, is the most demanding part of laparoscopic colorectal surgery with complex technical details. Accordingly, SFM has been shown to increase operative time and the incidence of splenic injury and other complications [12-14]. Splenic injury is a leading complication caused by SFM with a reported incidence of $0.5-8 \%$ and has been shown to have adverse effects on oncological outcomes. The incidence of splenic injury is remarkably lower in laparoscopic surgery compared to open surgery [15-18]. The procedure can be performed using a lateral-to-medial, medial-to-lateral, anterior, or combined approach. However, both SFM and the mobilization of the left colon are mostly performed using the medial-to-lateral approach. This approach enables immediate identification of the embryological plane and renders the dissection fast and safe. Moreover, after ligation of the vascular pedicle, tumor manipulation is minimized and the mesocolon can be rapidly freed from the retroperitoneal space without bleeding $[19,20]$.

\section{Aim}

In this study, we aimed to investigate the effect of SFM performed with a medial-to-lateral and superior-to-inferior approach on early clinical outcomes in laparoscopic resection of rectal cancer.

\section{Material and methods}

\section{Study design and patient selection}

The retrospective study included patients who underwent surgical treatment due to a diagnosis of rectal adenocarcinoma in our clinic between January 1, 2017 and December 31, 2018. The study was approved by the local ethics committee. Patients who underwent emergency surgery, open surgery, abdominoperineal resection, and partial SFM were excluded from the study. Each patient underwent oral and intravenous contrast-enhanced abdominal and pelvic computed tomography (CT), thoracic $\mathrm{CT}$, and pelvic magnetic resonance imaging (MRI) for tumor staging. Patients who had an early-stage tumor and were planned for transnasal excision underwent endorectal ultrasonography. Based on the indications, neoadjuvant CRT was performed according to current guidelines. The anastomotic line is below the pelvic reflection, or in case of neoadjuvant treatment, protective loop ileostomy is performed.

\section{Data collection}

Data were collected via patient registries, hospital database records, surgical notes, and final pathological reports. Demographic characteristics, neoadjuvant CRT performance, operative time, intraoperative blood loss and complications, postoperative complications, and length of hospital stay were recorded for each patient. Postoperative complications were classified based on the Clavien-Dindo classification [21]. Anastomotic leakage was defined as gas or fecal discharge from the incision line, vagina, or the drain tract, extravasation of contrast material and air bubbles around the anastomosis verified by rectal contrast-enhanced CT, and the presence of an anastomotic defect verified by laparotomy or rectal examination [22]. Evaluation of anastomotic stenosis was performed based on the presence of clinical suspicion. Anastomotic stenosis was defined as the inability to pass a $12-\mathrm{mm}$ diameter sigmoidoscope through the anastomosis within 6 months after the surgery. Tumor staging was performed according to the Union for International Cancer Control-American Joint Committee on Cancer (UICC-AJCC) TNM Classification System $7^{\text {th }}$ Edition [23]. Length of hospital stay was defined as the time from the initiation of surgery to hospital discharge.

\section{Surgical technique}

A camera port was entered in the supraumbilical site. Under direct view, five surgical ports were created, including a $12-\mathrm{mm}$ port in the lower right, a $5-\mathrm{mm}$ port in the upper right, a $5-\mathrm{mm}$ port in the upper left, and a 5-mm in the lower left quadrant and a 12-mm port in the suprapubic region (Photo 1). Following the surgical exploration of the abdomen, the patient was placed in a right-sided Trendelenburg position with the small bowel placed in the upper right quadrant. Dissection was initiated by retracting the descending colon and sigmoid colon 


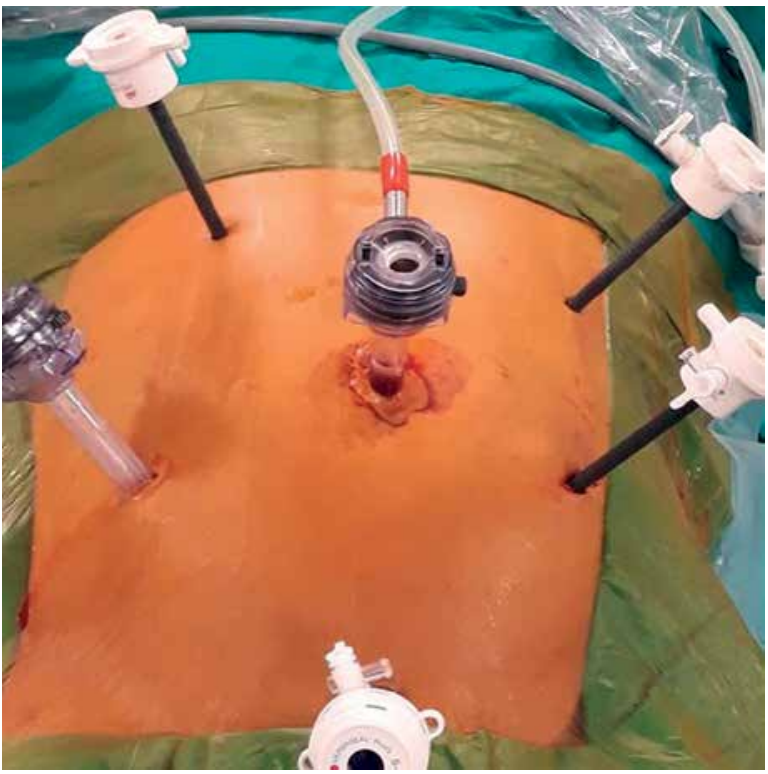

Photo 1. View of the port entrance area

and opening a window in the mesocolon lateral to the ligament of Treitz. The inferior mesenteric vein (IMV) was clipped and divided at the lower border of the pancreas. The middle colic artery (MCA) was preserved intact and the omental bursa was opened by dissecting the pancreatico-mesocolic ligament inferiorly from the upper border of the pancreas (Photo 2). The mesocolon was excised up to the level of the splenic hilum and was continued along the embryological fascial plane upward to the border of the inferior mesenteric artery (IMA), laterally along the retroperitoneal area up to Toldt's fascia. Subsequently, the IMA was clipped and divided (Photo 3). The mesocolon was released cranially to caudally and the presacral area was reached. Lateral peritoneal adhesions were dissected and the omentum was divided up until $2 / 3$ of the way along the transverse colon. The SFM procedure was completed by dividing all the splenocolic, phrenicocolic, gastrocolic, and pancreaticomesocolic ligaments. The surgical procedure was continued according to the standard TME procedure.

\section{Statistical analysis}

Data were analyzed using IBM SPSS for Windows version 21.0 (Armonk, NY: IBM Corp.). Descriptive data were expressed as mean \pm standard deviation (SD) or median (minimum-maximum) based on the distribution pattern of the variables.

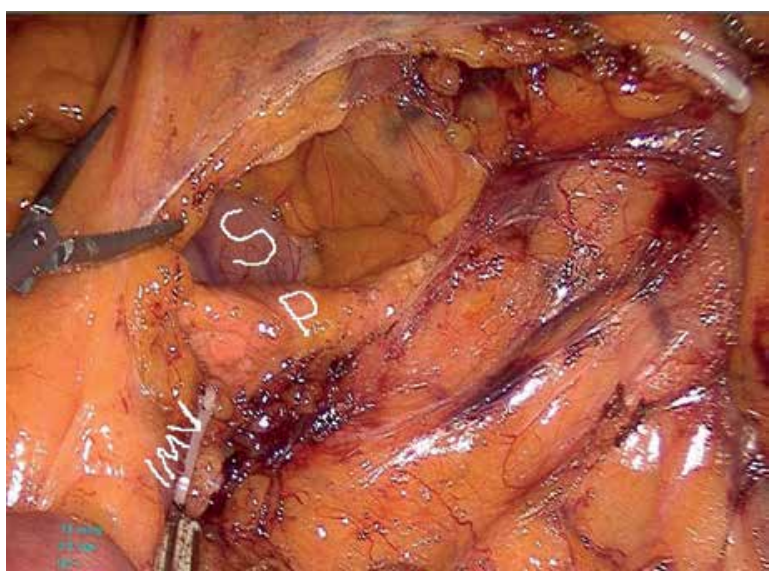

Photo 2. Ligation of the inferior mesenteric vein into the bursa omentalis cavity

IMV - inferior mesenteric vein, $P$ - pancreas, $S$ - stomach.

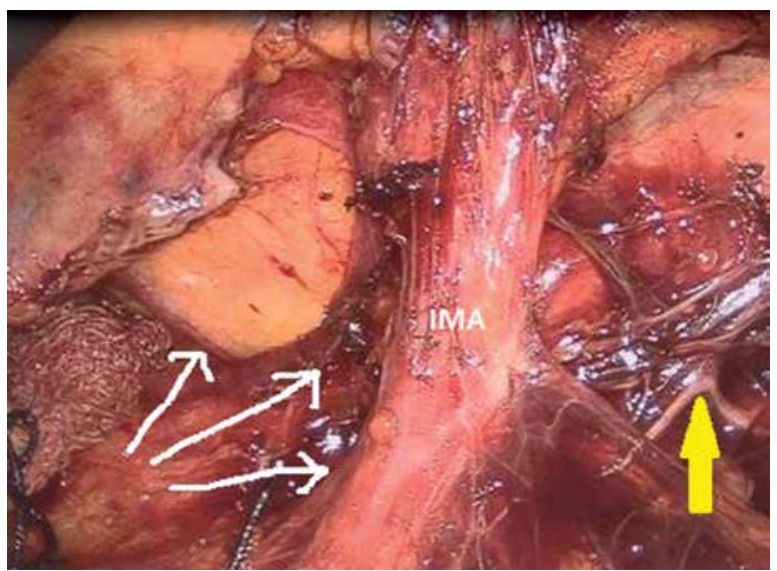

Photo 3. Isolation of the inferior mesenteric artery by cranial-to-caudal dissection, autonomic nerve structures (yellow arrow)

\section{Results}

The study reviewed medical records of 66 patients who were operated on due to rectal cancer in our clinic between January 2017 and December 2018. Of these, 23 patients who underwent abdominoperineal resection, open surgery, or total colectomy due to adenomatous polyposis of the colon were excluded and thus a total of 43 patients were included in the study (Figure 1). The patients included 26 (60.5\%) men and 17 (39.5\%) women with a mean age of $58.2 \pm 13.9$ (range: $30-87$ ) years. Comorbidities were present in 15 (34.8\%) patients, including diabetes mellitus (DM), hypertension, ischemic heart disease, and chronic obstructive pulmonary disease 


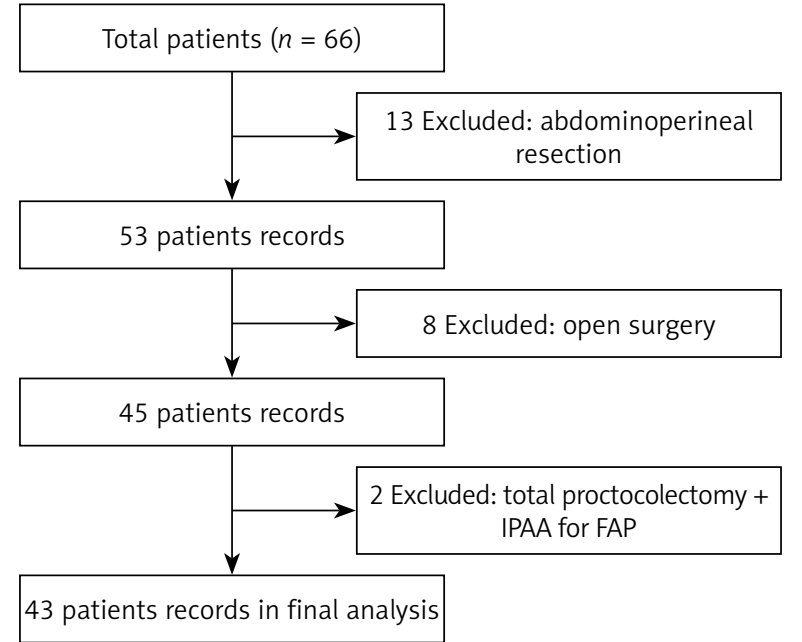

Figure 1. Flow chart of the study

(COPD). Thirty (69.8\%) patients had an ASA (American Society of Anesthesiologists) score of II. Table I presents the demographic, operative, and pathological characteristics of the patients. Mean operative time was $271 \pm 50$ min and mean blood loss was $144 \pm 83 \mathrm{ml}$. Two (4.7\%) patients underwent simultaneous metastasectomy for peripheral metastasis in the liver. A protective ileostomy was created in $37(86 \%)$ patients. Six (14\%) patients had stage 0 disease, of whom 5 patients showed a pathological complete response following CRT and the remaining one patient was diagnosed with tubulovillous adenoma with low-grade dysplasia.

No intraoperative splenic, pancreatic, ureteral, or adjacent organ injury occurred in any patient. Ileus was the most common postoperative complication ( $n=6 ; 14 \%)$, followed by bleeding ( $n=4 ; 9.3 \%)$, sepsis $(n=1 ; 2.3 \%)$, pulmonary embolism $(n=1$; $2.3 \%)$, atelectasis $(n=1 ; 2.3 \%)$, urinary retention $(n=1 ; 2.3 \%)$, evisceration ( $n=1 ; 2.3 \%)$, pancytopenia $(n=1 ; 2.3 \%)$, bladder fistula $(n=1 ; 2.3 \%)$, and anastomotic leakage $(n=1 ; 2.3 \%)$ (Table II). The patient with anastomotic leakage was receiving bevacizumab therapy due to metastatic disease prior to the surgery. The patient was operated on 7 weeks after the cessation of the bevacizumab therapy and the patient underwent low anterior resection, partial bladder resection, and metastasectomy for liver metastasis. After resuming the bevacizumab therapy postoperatively, the patient developed hypertension, wound site infection, sepsis, and bladder fistula in addition to anastomotic leakage. The patient was treated using conservative methods. Mean length of
Table I. Demographic, operative and pathological results of patients

\begin{tabular}{|c|c|}
\hline Variables & Result \\
\hline Age, mean \pm SD (range) [years] & $58.2 \pm 13.9(30-87)$ \\
\hline \multicolumn{2}{|l|}{ Gender, $n(\%)$ : } \\
\hline Male & $26(60.5)$ \\
\hline Female & $17(39.5)$ \\
\hline $\mathrm{BMI}$, mean $\pm \mathrm{SD}\left[\mathrm{kg} / \mathrm{m}^{2}\right]$ & $27.8 \pm 3.1$ \\
\hline \multicolumn{2}{|l|}{ ASA score, $n(\%)$ : } \\
\hline I & $8(18.6)$ \\
\hline$\|$ & $30(69.8)$ \\
\hline III & $5(11.6)$ \\
\hline \multicolumn{2}{|l|}{ Preoperative chemotherapy, $n$ (\%): } \\
\hline Yes & $24(55.8)$ \\
\hline No & $18(41.9)$ \\
\hline \multicolumn{2}{|l|}{ Preoperative radiotherapy, $n(\%)$ : } \\
\hline Yes & $22(51.2)$ \\
\hline No & $21(48.8)$ \\
\hline Diverting stoma, $n(\%)$ & $37(86)$ \\
\hline Duration of surgery, mean \pm SD [s] & $271 \pm 50$ \\
\hline Blood loss, mean \pm SD [ml] & $144 \pm 83$ \\
\hline Hospital stay, mean \pm SD [days] & $9.3 \pm 4.3$ \\
\hline \multicolumn{2}{|l|}{ UICC stage, $n(\%):$} \\
\hline 0 & $6(14)$ \\
\hline I & $16(37.2)$ \\
\hline$\|$ & $10(23.3)$ \\
\hline III & $9(20.9)$ \\
\hline IV & $2(4.7)$ \\
\hline
\end{tabular}

ASA - American Society of Anesthesiologists, BMI - body mass index, $S D$ - standard deviation.

hospital stay was $9.3 \pm 4.3$ (range: $5-28$ ) days and no early mortality occurred in any patient. No anastomotic stenosis was observed in any patient in the follow-up period.

\section{Discussion}

Splenic flexure mobilization is a complex part of laparoscopic colorectal procedures. A safe SFM not only achieves a tension-free colonic segment with 
a good blood supply but also increases compliance with oncological principles [9-11, 24]. The morbidity and adverse oncological outcomes associated with colorectal anastomotic leakage are well known. For this reason, the surgeon must pay appropriate attention to preventable risk factors for anastomotic leakage to create a safe anastomosis. Moreover, they should also recognize that the incidence of anastomotic leakage can be reduced by SFM $[9,11$, 25-27]. However, there are some studies in the literature advocating that SFM should be performed in selected cases due to its learning curve and complexity, prolonged operative time, and the increased risk for splenic, pancreatic, and adjacent organ injury $[6,7,12-14,16]$. Ferrara et al. reported that SFM increased the operative time, the incidence of conversion to open surgery, and the complexity of the operation. The authors also noted that SFM had no superiority in terms of postoperative complications and oncological outcomes [14]. In a recent systematic review, Nowakowski et al. reported that SFM led to a 3.2-fold increase in the operative time and a 3-fold increase in the incidence of anastomotic leakage compared to the patients who did not undergo SFM [7]. Inarguably, the absence of prospective, randomized, and controlled studies on SFM remains an important issue.

Splenic flexure mobilization is often required for the creation of a tension-free anastomosis with good blood supply in patients undergoing ultra-low anterior resection for middle and lower rectal cancer. Moreover, SFM may even become mandatory in patients requiring a colonic pouch [28]. Laparoscopy is highly advantageous since it allows a large dissection on the embryological plane without increasing the incidence of adjacent organ injury. Splenic flexure mobilization, on the other hand, increases the usable length of the colonic segment $[8,10,11]$. Mouw et al. [10] reported that SFM enabled adequate lymph node dissection and an adequate distal resection margin. The literature indicates that there are a number of risk factors associated with anastomotic leakage in low rectal cancer, including male gender, ASA score of $\geq I I$, neoadjuvant CRT, coronary artery disease, prolonged operative time, and intraoperative blood transfusion $[9,25]$. Kim et al. [9] reported that SFM is a highly valuable factor in the reduction of morbidity associated with anastomotic leakage and suggested that SFM should be used in laparoscopic resection of rectal cancer. It is
Table II. Postoperative complications

\begin{tabular}{|lll|}
\hline Complications & $N$ & $\%$ \\
\hline Paralytic ileus & 6 & 14 \\
\hline Wound infection & 4 & 9.3 \\
\hline Bleeding & 2 & 4.7 \\
\hline Atelectasis & 1 & 2.3 \\
\hline Sepsis & 1 & 2.3 \\
\hline Pulmonary embolism & 1 & 2.3 \\
\hline Urine retention & 1 & 2.3 \\
\hline Bladder fistula & 1 & 2.3 \\
\hline Evisceration & 1 & 2.3 \\
\hline Anastomotic leakage & 1 & 2.3 \\
\hline Bone marrow suppression & 1 & 2.3 \\
\hline Clavien-Dindo: & & \\
\hline 0 & 4 & 9.3 \\
\hline 1 & 21 & 48.8 \\
\hline 2 & 14 & 32.6 \\
\hline 3 & 4 & 9.3 \\
\hline 4 & & 0 \\
\hline
\end{tabular}

recommended to perform it as the standard stage of surgical training [24].

The literature indicates that there is no standardized approach for laparoscopic SFM. However, the medial-to-lateral approach has a shorter duration compared to the lateral approach, also causing no additional complications. By using the medial-to-lateral approach, dissection of the mesocolon following high vascular ligation can be rapidly performed with no bleeding. On the other hand, the higher magnification and high-definition resolution provided by laparoscopy allow better visualization of embryological and anatomic planes [8, 29]. Benseler et al. [5] reported that the lateral approach for SFM was associated with higher complication rates compared to the medial and anterior approaches. The authors also noted that the anterior approach had the lowest intra- and post-operative complication rates [5]. While employing the medial-to-lateral approach, surgeons often prefer to continue the dissection by preserving the ureter after isolating and dividing the IMA. In this way, however, the IMA is highly likely to be injured since it has a short origin arising from the 
aorta, it is difficult to isolate the IMA due to dense mesocolic fat, and the IMA is adjacent to autonomic nerve structures. For these reasons, the IMV, which can be visualized more easily, can be used as an anatomical landmark providing convenient points of reference for adjacent soft tissue structures, thereby facilitating the procedure [19].

In our clinic, SFM has been routinely performed in laparoscopic resection of rectal cancer since 2016. The primary step in our procedure consists of IMV ligation followed by the freeing of the pancreaticocolic ligament inferiorly from the upper border of the pancreas to the splenic hilum. In the second step, the mesocolon is freed caudally up to the margin of the IMA, followed by the ligation of the IMA. The dissection of the mesocolon is continued up to the presacral space in a superior-to-inferior and medial-to-lateral fashion. We consider that this procedure is advantageous in several ways: i) an appropriate anatomical plane is reached through the continuation of the dissection along IMV lateral to the ligament of Treitz followed by the ligation of the IMV at the lower border of the pancreas, ii) the dissection extending from the upper border of the pancreas to the splenic hilum is facilitated, iii) the superior-to-inferior dissection technique leads to a lower risk of adjacent organ injury as the dissection begins in a site distant from the ureter and gonadal vascular structures, and iv) the autonomic neurogenic structures can be preserved as the IMA can be visualized better in the site with dense mesocolic fat where it originates from the aorta. On the other hand, we believe that complete SFM reduces the complications, particularly those related to anastomosis. In our study, only 1 patient developed anastomotic leakage, which might have occurred secondary to bevacizumab therapy. However, no sign of anastomotic tension was noted intraoperatively and no anastomotic stenosis occurred in any patient during the follow-up period.

Our study was limited in several ways. First, it had a relatively small patient population and had no comparison group and thus it is difficult to propose generalizable results. However, we believe that SFM and the dissection of the mesocolon in a cranial-to-caudal and medial-to-lateral fashion are safe procedures and can be standardized. Additionally, the study had a retrospective design, no standard protocol was performed for the evaluation of anastomotic leakage, and no data were available regarding postoperative follow-up of the patients.

\section{Conclusions}

Based on the results of the study, we consider that SFM has potential to reduce the intra- and post-operative complications associated with anastomotic leakage in laparoscopic resection of rectal cancer. Therefore, SFM performed via the superior-to-inferior and medial-to-lateral approach appears to be a safe and feasible procedure. The surgical procedure can be initiated by the division of the IMV in a superior-to-inferior and medial-to-lateral fashion. Further comparative prospective studies investigating the standardization of SFM and elimination of controversies related to this procedure are needed.

\section{Conflict of interest}

The authors declare no conflict of interest.

\section{References}

1. Arnold M, Sierra MS, Laversanne M, et al. Global patterns and trends in colorectal cancer incidence and mortality. Gut 2017; 66: 683-91.

2. Heald RJ. The 'Holy Plane' of rectal surgery. J R Soc Med 1988; 81: 503-8.

3. Sauer R, Becker H, Hohenberger W, et al. Preoperative versus postoperative chemoradiotherapy for rectal cancer. N Engl J Med 2004; 351: 1731-40.

4. Sebag-Montefiore D, Stephens RJ, Steele R, et al. Preoperative radiotherapy versus selective postoperative chemoradiotherapy in patients with rectal cancer (MRC CRO7 and NCIC-CTG C016): a multicentre, randomised trial. Lancet 2009; 373: 811-20.

5. Benseler V, Hornung M, lesalnieks I, et al. Different approaches for complete mobilization of the splenic flexure during laparoscopic rectal cancer resection. Int J Colorectal Dis 2012; 27: 1521-9.

6. Gezen C, Altuntas YE, Kement M, et al. Complete versus partial mobilization of splenic flexure during laparoscopic low anterior resection for rectal tumors: a comparative study. J Laparoendosc Adv Surg Tech A 2012; 22: 392-6.

7. Nowakowski M, Małczak P, Mizera M, et al. The safety of selective use of splenic flexure mobilization in sigmoid and rectal resections-systematic review and meta-analysis. J Clin Med 2018; 7: pii: E392.

8. Vecchio R, Marchese S, Intagliata E. Laparoscopic colorectal surgery for cancer: what is the role of complete mesocolic excision and splenic flexure mobilization? Indian J Surg 2017; 79 : 338-43.

9. Kim CH, Lee SY, Kim HR, Kim YJ. Nomogram prediction of anastomotic leakage and determination of an effective surgical strategy for reducing anastomotic leakage after laparoscopic rectal cancer surgery. Gastroenterol Res Pract 2017; 2017: 4510561. 
10. Mouw TJ, King C, Ashcraft JH, et al.. Routine splenic flexure mobilization may increase compliance with pathological quality metrics in patients undergoing low anterior resection. Colorectal Dis 2019; 21: 23-9.

11. Kye BH, Kim HJ, Kim HS, et al. How much colonic redundancy could be obtained by splenic flexure mobilization in laparoscopic anterior or low anterior resection? Int I Med Sci 2014; 11: 857-62.

12. Akiyoshi T, Kuroyanagi H, Oya M, et al. Factors affecting difficulty of laparoscopic surgery for left-sided colon cancer. Surg Endosc 2010; 24: 2749-54.

13. Carlson RM, Roberts PL, Hall JF, et al. What are 30-day postoperative outcomes following splenic flexure mobilization during anterior resection? Tech Coloproctol 2014; 18: 257-64.

14. Ferrara F, Di Gioia G, Gentile D, et al. Splenic flexure mobilization in rectal cancer surgery: do we always need it? Updates Surg 2018; doi: 10.1007/s13304-018-0603-8.

15. Isik O, Aytac E, Ashburn J, et al. Does laparoscopy reduce splenic injuries during colorectal resections? An assessment from the ACS-NSQIP database. Surg Endosc 2015; 29: 1039-44.

16. Wang JK, Holubar SD, Wolff BG, et al. Risk factors for splenic injury during colectomy: a matched case-control study. World J Surg 2011; 35: 1123-9.

17. Malek MM, Greenstein AJ, Chin EH, et al. Comparison of iatrogenic splenectomy during open and laparoscopic colon resection. Surg Laparosc Endosc Percutan Tech 2007; 17: 385-7.

18. Wakeman CJ, Dobbs BR, Frizelle FA, et al. The impact of splenectomy on outcome after resection for colorectal cancer: a multicenter, nested, paired cohort study. Dis Colon Rectum 2008; 51: 213-7.

19. Pigazzi A, Hellan M, Ewing DR, et al. Laparoscopic medial-to-lateral colon dissection: how and why. J Gastrointest Surg 2007; 11: 778-82.

20. Veldkamp R, Gholghesaei M, Bonjer HJ, et al. Laparoscopic resection of colon cancer: consensus of the European Association of Endoscopic Surgery (EAES). Surg Endosc 2004; 18: 1163-85.

21. Dindo D, Demartines N, Clavien PA. Classification of surgical complications. Ann Surg 2004; 240: 205-13.

22. Aday U, Duman M, Deđer KC, et al. Endoscopic approach to anastomotic leaks: partially covered self-expandable stents. A single center's experience. Arch Med Sci Civil Dis 2017; 2: 29-34.

23. Edge SB, Byrd DR, Compton CC, et al. AJCC Cancer Staging Handbook. $7^{\text {th }}$ edn. Springer, New York 2010.

24. Ke TW, Geniales CR, Chen WT. The role of splenic flexure mobilization in laparoscopic rectal surgery for rectal cancer. Miniinv Surg 2018; 2: 35.

25. Gundes E, Cetin DA, Aday U, et al. Risk factors in anastomotic leaks after low anterior resection for rectal cancer and the effects of diverting stoma on clinical results. Turk J Colorectal Dis 2018; 28: 114-21.

26. Konish T, Watanabe T, Kishimoto J, Nagawa H. Risk factors for anastomotic leakage after surgery for colorectal cancer: results of prospective surveillance. J Am Coll Surg 2006; 202: 439-44.

27. Farke S, Bouchard R, Blumberg C, et al. Mobilization of the splenic flexure: a standard in laparoscopic left colon and rectum resections. Surg J 2010; 5: 31-5.
28. Fazio VW, Zutshi M, Remzi FH, et al. A randomized multicenter trial to compare long-term functional outcome, quality of life, and complications of surgical procedures for low rectal cancers. Ann Surg 2007; 246: 481-8.

29. Kim HJ, Kim CH, Lim SW, et al. An extended medial to lateral approach to mobilize the splenic flexure during laparoscopic low anterior resection. Colorectal Dis 2013; 15: 93-8.

Received: 6.03.2019, accepted: 17.04.2019. 